\title{
Drug Induced Gingival Hyperplasia
}

National Cancer Institute

\section{Source}

National Cancer Institute. Drug Induced Gingival Hyperplasia. NCI Thesaurus. Code C97082.

Overg rowth of the gingival tissue caused by phenytoin, cyclosporine A, and calcium channel blockers. 